\title{
The protein-coding region of c-myc mRNA contains a sequence that specifies rapid mRNA turnover and induction by protein synthesis inhibitors
}

\author{
Ron Wisdom ${ }^{1}$ and William Lee $^{2}$ \\ ${ }^{1}$ Molecular Biology and Virology Laboratory, The Salk Institute, San Diego, California 92138; ${ }^{2}$ Division of \\ Hematology/Oncology, Department of Medicine and the Cancer Center, Hospital of the University of Pennsylvania, \\ Philadelphia, Pennsylvania 19104 USA
}

The stability of certain mRNAs is known to be affected by translation. Some mRNAs appear to be protected from rapid degradation by translation, whereas degradation is coupled to translation for other mRNAs. The molecular determinants of this selective effect of translation are unknown. One example of this effect is the induction of early-response gene mRNAs in the presence of translation inhibitors. To define the molecular basis of induction of early-response gene mRNA expression by inhibitors of protein synthesis, we have performed a mutational analysis of one member of the early response gene family, the c-myc gene. We find that induction by cycloheximide is due to stabilization of $c-m y c$ transcripts. The requirements for increased expression of c-myc mRNA by cycloheximide are the presence of the sequence encoding c-myc amino acids 335-439 on a mRNA that can be translated; all other portions of the c-myc gene are dispensable, and this sequence can confer induction of mRNA expression by protein synthesis inhibitors on a heterologous gene. By direct measurement of mRNA turnover in the absence of transcription-blocking drugs, we show that this sequence can function as a selective mRNA destabilizing element, that turnover mediated by this element is translation dependent, and turnover mediated by this element is inhibited by actinomycin D. Our results support the hypothesis that degradation of c-myc mRNA is coupled to translation, that the sequences specifying this form of degradation are contained in the protein-coding sequence, and that translation inhibitors induce expression of c-myc mRNA by blocking turnover mediated by this element.

[Key Words: c-myc mRNA; mRNA stability; translation inhibitors]

Received September 24, 1990; revised version accepted November 19, 1990.

Regulation of eukaryotic mRNA expression can theoretically occur at any step in the biogenesis of the mRNA: synthesis of the primary transcript, splicing, processing [addition of the $5^{\prime} 7$ methyl $G$ cap and $3^{\prime}$ poly(A) residues], transport from the nucleus to the cytoplasm, and degradation of the mRNA, whether in the nucleus or cytoplasm. Examples have been described that demonstrate regulation in each of these processes, and it is clear that the steady-state level of some mRNAs is regulated in large part at the level of mRNA turnover.

Little is known about the process of mRNA turnover. Relatively few mRNAs have been studied in detail, and the determinants that specify rapid or slow mRNA turnover are poorly defined. For some mRNAs, degradation begins within the poly $(\mathrm{A})$ tail and proceeds into the body of the mRNA, but it has been difficult to isolate and characterize intermediates in the process /Wilson and Treisman 1988; Swartout and Kinniburgh 1989). There is data to support the idea that the sequence AUUUA in the 3 '-untranslated region of certain mRNAs plays a role in specifying rapid turnover (Shaw and Kamen 1986; Schuler and Cole 1988), but this sequence is not sufficient to ensure rapid turnover, as many stable mRNAs, such as rabbit $\beta$-globin, also contain this sequence in their $3^{\prime}$-untranslated region. There is also evidence to support the idea that translation of mRNAs plays a role in determining the rate at which those mRNAs are degraded. For example, the mRNAs for $\beta$-globin, $\mu$-heavy chain, and triose phosphate isomerase are very stable, and mutations that cause premature termination of translation result in unstable mRNAs, suggesting that translated mRNAs are protected from degradation (Maquat et al. 1981; Bauman et al. 1985; Daar and Maquat 1989|. In contrast, degradation of the mRNAs for $\beta$-tubulin, histone, and transferrin receptor is coupled to translation, so that the addition of translation inhibitors slows their turnover, and mutant mRNAs that cannot be translated are degraded more slowly (Graves et al. 1987; Pachter et al. 1987; Mullner and Kuhn 1988). The molecular determinants that specify whether the turnover 
of a particular mRNA will be either enhanced or slowed by translation are not known.

One example of the effect of translation on mRNA stability may be the increase in mRNAs from the earlyresponse genes induced by inhibitors of translation. The transition of cells from the resting state, $\mathrm{G}_{0}$, into the cell cycle is accompanied by a coordinate increase in the expression of a set of genes termed early-response genes. Recently, several groups have identified a large number of early-response genes from quiescent 3T3 cells stimulated to divide with serum (Lau and Nathans 1987; Almendral et al. 1988). Aside from their defining property, induction by mitogens, the regulation of expression of these genes shows that they share one other feature, namely, they are all induced by treating cells with protein-synthesis inhibitors (Lau and Nathans 1987; Almendral et al. 1988; Chavrier et al. 1988). The mRNAs derived from the early-response genes are in general short lived, and a marked stabilization of these transcripts occurs in the presence of protein-synthesis inhibitors (Almendral et al. 1988). Thus, for many of the earlyresponse genes, induction by protein-synthesis inhibitors occurs, at least in part, by slowing turnover of the mRNAs. The mechanism by which these transcripts are stabilized by protein-synthesis inhibitors remains unknown.

The c-myc gene is one member of the family of earlyresponse genes. It is typical of the early-response genes in the following respects: (1) Expression of c-myc mRNA is induced from 10- to 40-fold when many types of quiescent cells are treated with growth factors or mitogens (Kelly et al. 1983); 2) c-myc mRNA is induced by inhibitors of protein synthesis, and superinduced by serum and protein-synthesis inhibitors (Kelly et al. 1983); and 3) neither serum nor protein-synthesis inhibitors increase c-myc transcription enough to account for the change in the steady-state level of mRNA /Greenberg and Ziff 1984; Linial et al. 1985; Nepveu et al. 1987a) and therefore, regulation is presumably post-transcriptional. It has been shown previously that protein-synthesis inhibitors slow the turnover of c-myc mRNA (Linial et al. 1985).

The observation that protein-synthesis inhibitors slow the turnover of $c-m y c$ mRNA suggests that the degradation of c-myc mRNA may be coupled to translation. We have characterized the mechanism of induction of c-myc mRNA by protein-synthesis inhibitors. We show that this induction occurs without changes in the level of transcription; instead, induction of c-myc mRNA by protein-synthesis inhibitors is the result of stabilizing an otherwise labile mRNA. The molecular requirements for this are the presence of the sequence encoding c-myc amino acids 335-439 on a mRNA molecule that can be translated; all other portions of c-myc mRNA are dispensable. We show further that the presence of this sequence can confer rapid turnover on an otherwise stable mRNA, that turnover mediated by this sequence is coupled to translation, and that the ability of this sequence to induce rapid mRNA turnover is inhibited by actinomycin $\mathrm{D}$. The sequence we have characterized encodes the recently described helix-loop-helix (HLH) domain capable of mediating protein-protein interactions (Murre et al. 1989). The implications of these results with regard to the effects of translation on mRNA stability and the induction of $c-m y c$ mRNA by mitogens are discussed.

\section{Results}

Induction of c-myc mRNA by cycloheximide is post-transcriptional

All experiments were carried out in growing mouse C2 myoblasts. Although these cells have the capacity to differentiate into skeletal muscle myotubes when grown to confluence, they have a fibroblast-like appearance when maintained as myoblasts. Furthermore, when serum is added to the media after the cells have been deprived of serum for $48 \mathrm{hr}$, they show induction of several earlyresponse genes, including c-myc and c-fos, to a level similar to that seen in $3 \mathrm{~T} 3$ cells (data not shown). To measure the induction of $\mathrm{c}-\mathrm{myc}$ mRNA by protein-synthesis inhibitors, cycloheximide $(10 \mu \mathrm{g} / \mathrm{ml})$ was added to the culture media, and total cellular RNA isolated at different time points was analyzed for c-myc mRNA expression by Northern blotting. Treatment of $\mathrm{C} 2$ cells with cycloheximide results in a rapid increase in c-myc mRNA (Fig. la), as has been described in a variety of other cell types. In different experiments, this induction ranged from 10 - to 30 -fold at $3 \mathrm{hr}$ as measured by scanning densitometry. There is no evidence of a larger transcript that might represent unspliced RNA. This result is not specific to cycloheximide, as treatment of $\mathrm{C} 2$ cells with emetine, another inhibitor of protein synthesis, resulted in a similar induction (data not shown).

To define the level of regulation of this increased expression, nuclear run-on assays were performed. Nuclei isolated from cells in the presence or absence of cycloheximide were used to generate radiolabeled run-on probes that were then hybridized to single-stranded DNA corresponding to different regions of the c-myc gene. The results are shown in Figure $1 \mathrm{~b}$. There is no change in the rate of transcription in either c-myc exon one or exon two following treatment with cycloheximide, although some attenuation of transcription is observed under both conditions, a phenomenon that has been described previously (Bentley and Groudine 1986; Nepveu et al. 1987b). This experiment demonstrates that the increase in c-myc mRNA following treatment of cells with cycloheximide is not due to an increase in transcription of the gene and suggests the existence of a post-transcriptional mechanism. To test this hypothesis, we measured the half-life of c-myc mRNA in the presence and absence of cycloheximide using actinomycin $\mathrm{D}$, a drug that blocks transcription. Following a lag time of $\sim 30 \mathrm{~min}$ before any effect of the actinomycin $\mathrm{D}$ is seen, there is a rapid decay in the amount of c-myc mRNA in untreated cells, with a half-life of $\sim 15 \mathrm{~min}$ (Fig. 1c). In contrast, c-myc mRNA is degraded much more slowly in cells treated with cycloheximide, with 

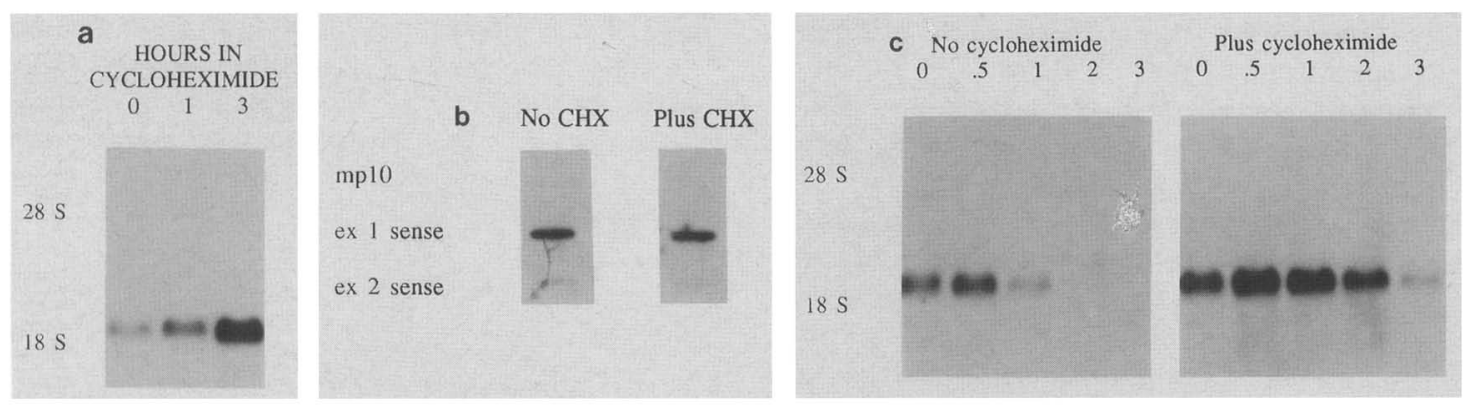

Figure 1. (a) Induction of c-myc mRNA by cycloheximide. Cycloheximide $(10 \mu \mathrm{g} / \mathrm{ml})$ was added to subconfluent $\mathrm{C} 2 \mathrm{myoblasts} 24 \mathrm{hr}$ after the last change of media. Total cellular RNA was then isolated at various time points and separated on formaldehyde-agarose gels $(10 \mu \mathrm{g} / \mathrm{sample})$. Samples were visualized by staining with ethidium bromide to be certain that equal amounts of RNA were loaded. Samples were then analyzed for expression of $c-m y c$ mRNA by Northern blotting and hybridization with a human c-myc cDNA probe. The positions of the rRNAs are indicated at left. $|b|$ Nuclear run-on assay of c-myc transcription in the presence and absence of cycloheximide. Nuclei were isolated from subconfluent C2 myoblasts before and $1 \mathrm{hr}$ after the addition of cycloheximide. Run-on transcripts were labeled in vitro with $\left[{ }^{32} \mathrm{P}\right]$ UTP, and the radiolabeled RNA was isolated and used as a probe. Single-stranded target DNA samples were used to ensure that only sense-direction transcripts were detected. Target DNA samples were the BamHI fragment of mouse c-myc exon 1 in an orientation to detect sense transcripts (exon 1 sense); the Pst Iragment of mouse c-myc exon 2 in an orientation to detect sense transcripts (exon 2 sense); and M13 mp10 DNA. Hybridization conditions are described in Materials and methods. (c) Stability of c-myc transcripts in the absence and presence of cycloheximide. Actinomycin D (10 $\mu \mathrm{g} / \mathrm{ml}) \mathrm{was}$ added to C2 cells in either the absence (left $)$ or presence of cycloheximide $(10 \mu \mathrm{g} / \mathrm{ml}$; added $15 \mathrm{~min}$ before actinomycin D). Total cellular RNA was isolated at various time points after the addition of actinomycin $\mathrm{D}$ and separated on formaldehyde-agarose gels. Expression of $\mathrm{c}$-myc mRNA was detected by hybridization with a c-myc cDNA probe. Numbers refer to hours after addition of actinomycin D.

essentially no change in the first $2 \mathrm{hr}$ (Fig. 1c). These results confirm the data of Linial et al. (1985), who showed that induction of $\mathrm{c}-\mathrm{myc}$ mRNA in the presence of cycloheximide is due to a stabilization of the normally unstable c-myc mRNA and cannot be accounted for by increased transcription of the gene.

\section{$m R N A$ from a transfected human c-myc gene is induced by cycloheximide}

To define more clearly the mechanism of induction of c-myc mRNA by protein-synthesis inhibitors, we have performed a mutational analysis. An $8.7-\mathrm{kb}$ human cmyc genomic clone containing $2.3 \mathrm{~kb}$ of upstream sequence and $800 \mathrm{bp}$ of downstream sequence was introduced into $\mathrm{C} 2$ cells by cotransfection with the plasmid pSV2neo. A pool of transfectants isolated by selection in G418 was analyzed for expression of the endogenous mouse c-myc gene and the transfected human c-myc gene following treatment with cycloheximide. Figure 2a demonstrates that the amount of c-myc mRNA from the transfected human gene as well as the endogenous mouse gene increase following treatment with cycloheximide, and the increase shows similar kinetics. We conclude that the sequences required in cis for this regulation are contained in the $8.7-\mathrm{kb}$ transfected human $\mathrm{c}$ myc gene.

The c-myc protein-coding sequence is required for induction by protein-synthesis inhibitors

Because we wished to delete functional subunits of the c-myc gene, it was necessary to define a gene that did not respond to cycloheximide with a change in its expres- sion. For this purpose, we chose the plasmid MLV-CATSVpA. The transcription unit contained in this plasmid is comprised of the Moloney murine leukemia virus long terminal repeat (MLV-LTR) serving as a promotor/enhancer, the coding region of the bacterial gene encoding chloramphenicol acetyltransferase (CAT), and transcrip-
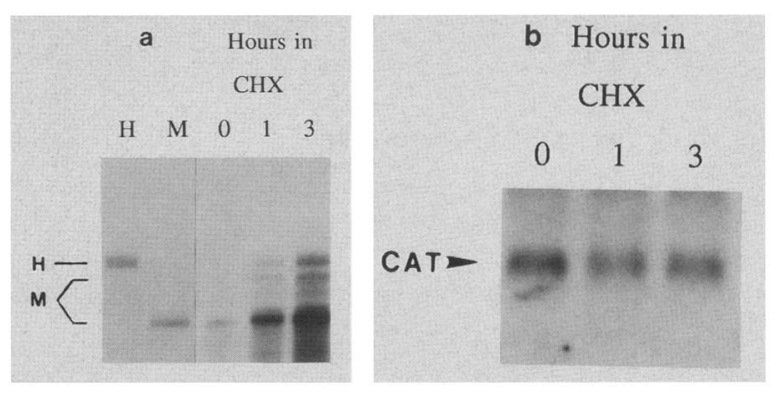

Figure 2. Expression of the normal human $c-m y c$ gene is induced by cycloheximide. (a) An $8.7-\mathrm{kb}$ human $\mathrm{c}-\mathrm{myc}$ genomic clone was transfected into C2 cells. Total RNA was isolated from transfectants at different time points after the addition of cycloheximide as before. Samples of RNA (25 $\mu \mathrm{g} / \mathrm{sample}$ ) were analyzed for mRNA from the transfected human gene and the endogenous mouse gene using an RNase protection assay. $\mathrm{Hu}$ man c-myc mRNA protects 420 -bp fragment of the human probe; mouse c-myc mRNA yields protected fragments of 402 and 354 bp from the mouse probe. Lanes are as follows: $(H) 10$ $\mu \mathrm{g}$ HeLa cell RNA; $(M) 20 \mu \mathrm{g}$ untransfected C2 cell RNA; $(0,1$, and 3 ) hours after addition of cycloheximide to transfected cells. (b) The plasmid MLV-CAT-SVpA was introduced into C2 cells. RNA was isolated from cells stably transfected with the plasmid MLV-CAT-SVpA at different points after the addition of cycloheximide to the media and analyzed for the presence of CAT transcripts using Northern blotting. The PvuII-ScaI fragment of the CAT-coding sequence was used as probe. 
tion termination and polyadenylation signals supplied by sequences derived from the early region of the SV40 virus. Figure $2 b$ shows that there was no effect of cycloheximide treatment on the expression of CAT mRNA. To further exclude the possibility that transcription initiation from the MLV-LTR is induced by cycloheximide, we performed nuclear run-on assays on CAT-expressing cells in the presence and absence of cycloheximide; no change was observed (data not shown). These experiments demonstrate that expression of mRNA from the plasmid MLV-CAT-SVpA is not affected by cycloheximide, and this plasmid can therefore serve as a substrate in the generation of chimeric genes with the human c-myc gene.

Our earlier analysis suggested that the increase in cmyc expression was not due to increased transcription. To test this further, the plasmid pM21, in which the c-myc upstream region has been replaced by the MLVLTR, was introduced into $\mathrm{C} 2$ cells and regulation of the mRNA expressed from this plasmid was compared with the expression of mRNA from the endogenous locus. Figure $3 \mathrm{~A}$ shows that the mRNAs derived from the endogenous mouse gene and the transfected human gene under the control of a foreign promotor are induced by cycloheximide with similar kinetics. We conclude that induction of $c-m y c$ mRNA by cycloheximide does not require the c-myc upstream sequences, consistent with our earlier data showing that this regulation does not occur at the level of transcription initiation.

To further define the region conferring responsiveness to cycloheximide, a series of c-myc recombinant genes were introduced into $\mathrm{C} 2$ cells. In each of these plasmids, the c-myc upstream sequences have been replaced with the MLV-LTR. These plasmids contain deletions of cmyc exon one (MLV-m23), of all sequences present in the $c-m y c$ mRNA except the protein-coding sequences and 5 bp immediately upstream of the translation initiation site (MLV-m23-SVpA), or of the sequences in c-myc mRNA that encode the c-myc protein (MLV-mCATm3'). Expression of mRNA derived from these plasmids was analyzed in the presence and absence of cycloheximide. mRNA derived from the plasmid MLV-m23 is induced to the same degree as the endogenous gene (Fig. 3B), as is mRNA from the plasmid MLV-m23-SVpA (Fig. 3C). Expression of mRNA from the plasmid MLV-mCATm3' is not induced in response to cycloheximide (Fig. 3D). We draw several conclusions from this analysis. First, consistent with the nuclear run-on data (Fig. lb), regulation does not occur by a change in the attenuation of transcription at the exon 1/intron 1 junction, as mutants lacking this sequence are induced (Fig. 3B,C). Second, splicing is not required for increased expression in response to cycloheximide, as mutants that do not generate spliced $m R N A$ are induced (Fig. 3B,C). Third, neither the c-myc 5'-leader sequence nor the 3'-untranslated region, both of which have been suggested to have a role in conferring a rapid turnover on c-myc mRNA (Jones and Cole 1987), are required for increased expression of the mRNA in response to cycloheximide, as mutants that do not contain these sequences are induced to a degree similar to the endogenous gene (Fig. 3B,C). Fourth, the c-myc protein-coding sequence plus 5 bp upstream of the trans-

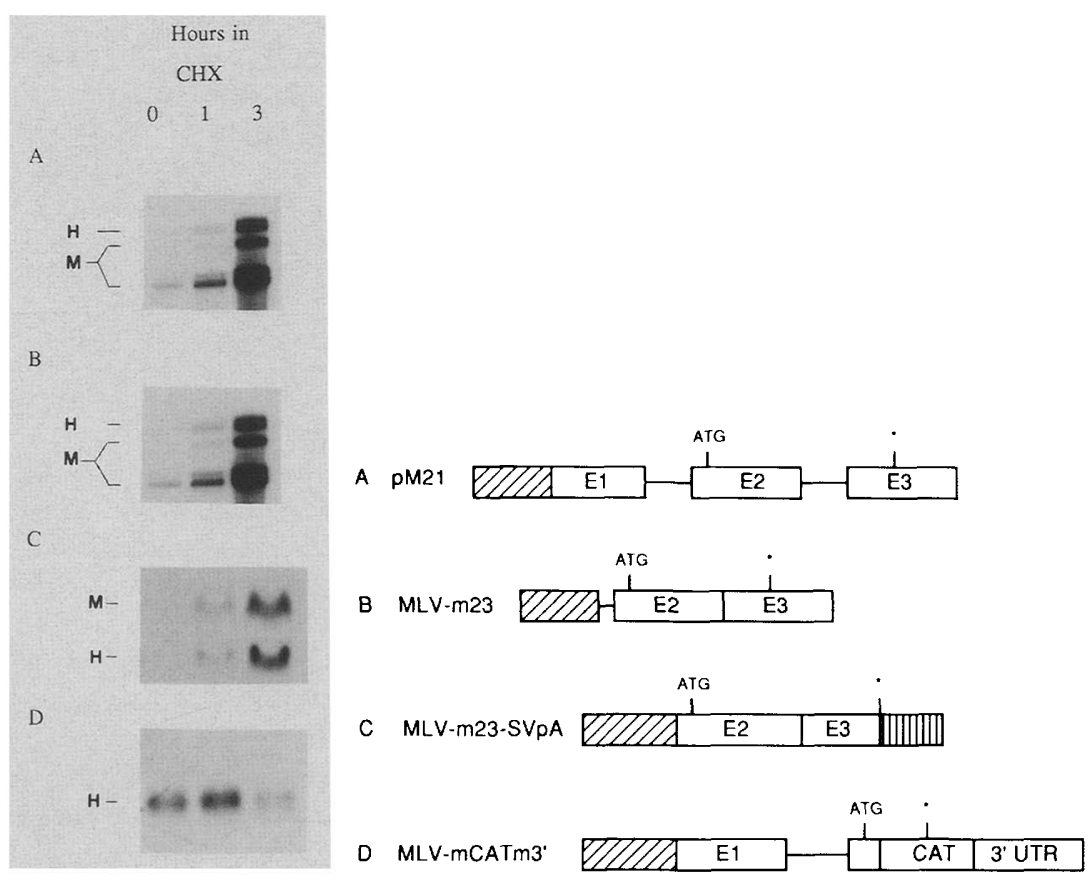

Figure 3. Inducibility of mRNA from mutant c-myc genes in the presence of cycloheximide. Different c-myc mutant genes were introduced into cells, and stable transfectants were isolated. RNA was isolated from transfectants at different time points after the addition of cycloheximide and expression of mRNA from both the transfected gene and the endogenous gene was analyzed. $($ Left $t)$ The test plasmids were $|A|$ pM21; (B) MLV-m23; (C) MLV-m23-SVpA; $(D)$ MLV-mCATm $3^{\prime}$. RNA was analyzed using either an RNase protection assay $\mid A$ and $B \mid$ or Northern blotting $(C, D)$. $(H)$ Bands representing transcripts from the transfected human gene; $(M)$ bands representing transcripts from the endogenous mouse c-myc gene. The probes used in the RNase protection assay and the length of protected fragments are described in Fig 2. A nick-translated human c-myc cDNA probe was used in $C$. The probe used in $D$ was a fragment of the CAT protein-coding sequence. (Right) Schematic diagrams of the transfected plasmids. The crosshatched box represents the MLV-LTR; the vertical lined box represents the SV40 early region polyadenylation signal (HincII-BamHI fragment); other boxes are marked; 3' UTR represents the c-myc $3^{\prime}$-untranslated region; the asterisk marks the termination codon. 
lation initiation site are sufficient to result in induction of c-myc mRNA in response to cycloheximide (Fig. 3C). Finally, the $5^{\prime}$-leader sequence and the $3^{\prime}$-untranslated region cannot confer regulation on a heterologous gene (Fig. 3D). If induction of c-myc mRNA by cycloheximide occurs by stabilizing a normally unstable mRNA, as shown by the data in Figure 1, these results imply that c-myc mRNAs that do not contain the 3' AU-rich untranslated region are unstable, a result in disagreement with previously published data (Jones and Cole 1987). This paradox will be addressed.

\section{$c$-myc mRNA must be translated for induction by cycloheximide}

Our results showing that the presence of the c-myc protein-coding sequence is necessary and sufficient for induction by cycloheximide suggested that translation of c-myc mRNA might be required for this effect to be observed. To test this possibility, we constructed the plasmid MLV-ATCm23-SVpA, which is identical to the plasmid MLV-m23-SVpA except for a point mutation that changes the translation initiation codon from ATG to ATC. It should be noted that the CTG initiation codon in exon one that gives rise to a minor species of c-myc protein (Hann et al. 1988) is not present in either of these plasmids. The mRNA derived from MLV-ATCm23SVPA is not induced efficiently (there is a 1.5 -fold increase as measurcd by densitometryl, although a 10 -fold induction of the endogenous mouse mRNA is observed (Fig. 4). Although it is possible that translation initiation from downstream AUGs occurs (in either the correct or incorrect reading frame), we feel this is unlikely for two reasons. First, no other ATG is surrounded by a consensus sequence for mammalian translation initiation (Kozak 1981), and second, mRNAs derived from this plasmid are not bound to polyribosomes, although $\mathrm{mR}$ NAs from the endogenous c-myc gene are (data not shown). From this experiment we conclude that efficient

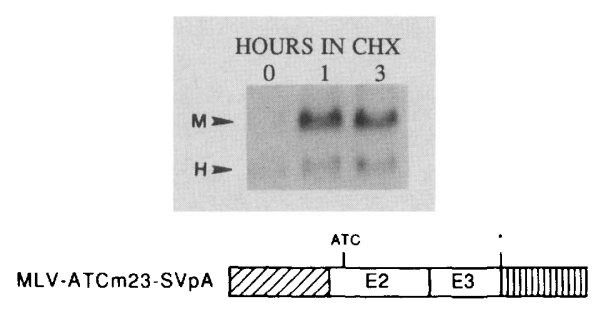

Figure 4. Inducibility of mRNA from a c-myc gene containing a mutation in the translation initiation codon. The translation initiation codon of the plasmid MLV-m23-SVpA was changed from ATG to ATC by site-directed mutagenesis to create the plasmid MLV-ATCm23-SVpA. This plasmid was introduced into cells, and expression of mRNA from the transfected and endogenous genes was analyzed in the absence and presence of cycloheximide. (Top) (M) Transcripts from the endogenous mouse gene; $(\mathrm{H})$ transcripts from the transfected gene. (Bottom) A schematic diagram of the plasmid. Symbols are explained in the legend to Fig. 3 . induction by cycloheximide requires $\mathrm{c}-\mathrm{myc}$ mRNA to be in a form that can be translated efficiently. These results are consistent with a model in which degradation of $\mathrm{c}$ myc mRNA is coupled to translation; the addition of inhibitors of translation would then result in the accumulation of c-myc mRNA. According to this model, cmyc mRNAs that are not translated would not accumulate in the presence of inhibitors of translation because turnover of these mRNAs would be uncoupled from translation.

The sequence encoding c-myc amino acids 335-439 confers efficient induction by protein synthesis inhibitors

To further localize the sequences required for increased $c$-myc mRNA expression in response to protein synthesis inhibitors, a series of mutants containing in-frame deletions in the c-myc protein-coding sequence were generated within the plasmid MLV-m23Nsi-SVpA. Stable transfectants were analyzed for expression of the mutant c-myc genes in the presence and absence of cycloheximide; the results are shown in Figure 5. Expression of mRNA from most of the deletion mutants was induced to the same degree as the endogenous gene. Induction was markedly impaired for deletion mutant D371412 (1.5-fold induction at $3 \mathrm{hr}$ ), and was somewhat decreased for deletion mutant D312-368 /sixfold induction at $3 \mathrm{hr}$ ). In contrast, the mRNA from all other deletion mutants was induced more than 10 -fold. We conclude that the sequence encoding c-myc amino acids $371-412$ is required for efficient induction by protein-synthesis inhibitors, and mutants with deletions of the sequenceencoding c-myc amino acids 312-368 show somewhat diminished inducibility.

To test the ability of this sequence to confer induction on a heterologous gene, the control plasmid MLV-CAT. SVpA, which is not inducible by cycloheximide (Fig. 2b), was modified by the addition of $c-m y c$ sequences. The plasmid MLV-CAT-m335-SVpA contains a CAT-myc fusion gene encoding a peptide comprised of CAT amino acids 1-210 fused in-frame to c-myc amino acids 335439; the LTR promotor and SV40 polyadenylation sequences remain the same. Expression of the fusion gene was measured in the presence and absence of cycloheximide (Fig. 6). The presence of the c-myc sequence-encoding amino acids $335-439$ in the proper reading frame is sufficient to confer efficient induction by cycloheximide on a heterologous gene. That not all CAT-myc fusion genes are inducible by cycloheximide is shown in Figure 5. mRNA from the plasmid mycl-103CAT is not induced by cycloheximide, demonstrating that the sequence encoding c-myc amino acids $1-103$ is not sufficient to confer induction by cycloheximide. These results, together with the deletion analysis shown in Figure 5, demonstrate that the sequence encoding c-myc amino acids 335-439, when present on a mRNA that can be translated, dn function in cis to confer induction by protein-synthesis inhibitors. If this induction results from stabilizing a labile mRNA, these results imply that 


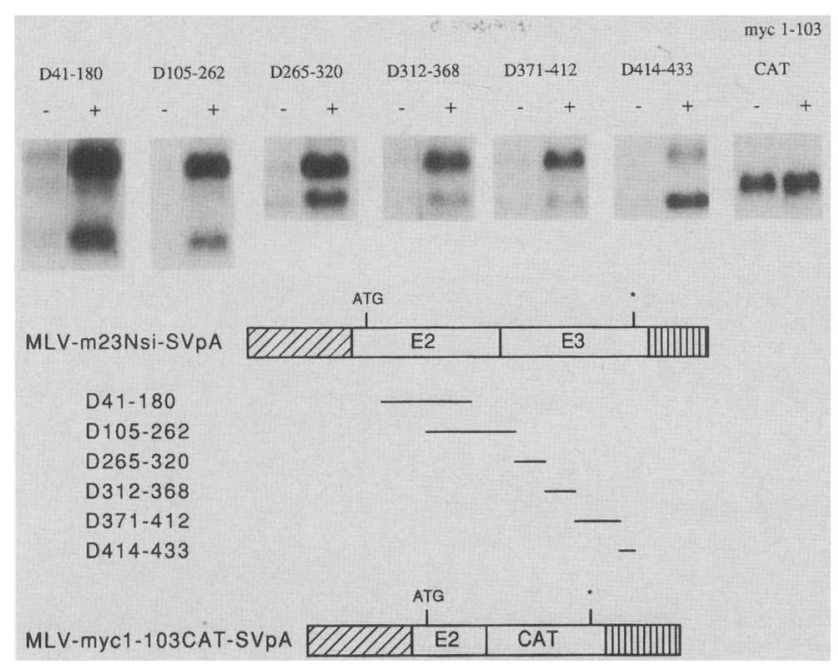

Figure 5. Inducibility of mRNA from c-myc genes containing deletions in the protein-coding sequence. Derivatives of the plasmid MLV-m23Nsi-SVpA (see Materials and methods) containing different in-frame deletions of the c-myc protein-coding sequence were introduced into cells, and expression of mRNA from the recombinant and endogenous genes in the absence $(-)$ or the presence $(+)$ of cycloheximide for $3 \mathrm{hr}$ was analyzed by Northern blotting. $\mathrm{D}$ is followed by numbers indicating the amino acids deleted within each of the mutant c-myc genes. The top band in each panel represents transcripts from the endogenous mouse c-myc gene; the lower band represents transcripts from the recombinant human c-myc gene. The possible importance of the sequence encoding the amino terminus of the protein was assessed by generating a myc-CAT fusion gene (MLV-mycl-103CAT-SVpA) containing the sequences encoding c-myc amino acids $1-103$ joined in-frame to CAT-coding sequences. Detection of transcripts from the myc-CAT fusion gene was with a CAT probe; the endogenous mouse c-myc transcripts are not detected. Schematic diagrams of the test plasmids are shown; all deletion mutants were made in MLV$\mathrm{m} 23 \mathrm{Nsi}-\mathrm{SVpA}$; the thin lines represent the deletions present in the corresponding plasmid. The symbols are explained in the legend to Fig. 3.

this sequence constitutes an element that renders $m R$ NAs containing it unstable in the absence of proteinsynthesis inhibitors, and stable in their presence.

The element that confers responsiveness to cycloheximide encodes a mRNA-destabilizing sequence

The data from the mutagenesis studies presented above are consistent with the hypothesis that inducibility of c-myc mRNAs by inhibitors of protein synthesis is a consequence of stabilizing a labile transcript accompanied by a constant rate of transcription. Such a model implies that c-myc genes that are inducible by proteinsynthesis inhibitors encode labile mRNAs, including genes with truncations of the c-myc $5^{\prime}$ - and 3 '-untranslated regions such as MLV-m23-SVpA (Fig. 3c). Studies of mRNA turnover using actinomycin D show that mRNA derived from this mutant is degraded slowly, with a half-life $\sim 2.5 \mathrm{hr}(\mathrm{R}$. Wisdom and W. Lee, unpubl.; for similar results, see Jones and Cole 1987). This rate of turnover is too slow to account for a 10- to 30-fold increase in the steady-state mRNA level in $3 \mathrm{hr}$ simply by stabilizing the mRNA. Previous investigators have shown, however, that actinomycin $\mathrm{D}$ can slow the turnover of certain labile mRNAs. For example, the removal of iron-chelating drugs from the media results in a rapid decrease in the level of transferrin receptor (TfR) mRNA from cells in tissue culture; treatment with actinomycin D prevents this decay (Mullner and Kuhn 1988). Similarly, actinomycin D slows the turnover of certain mutant c-fos mRNAs following serum induction (Shyu et al. 1989). We therefore sought to measure the half-life of truncated c-myc mRNAs in the absence of actinomycin D or other transcription-blocking drugs.

To measure the half-life of truncated c-myc mRNAs without using actinomycin $\mathrm{D}$, the $\mathrm{c}-\mathrm{myc}$ protein-coding sequence and SV40 polyadenylation signal from the plasmid MLV-m23-SVpA were placed downstream of a fragment containing the human c-fos promotor. The fragment used contains the well-characterized dyad symmetry element (DSE), which is capable of conferring transient induction of transcription following serum stimulation of serum-starved cells (Deschamps et al. 1985; Treisman 1985). Cells stably transfected with the resulting plasmid $\mathrm{FC4}-\mathrm{m} 23-\mathrm{SV}$ A were grown in media containing $0.5 \%$ FCS for $48 \mathrm{hr}$, after which time the media was replaced with media containing $10 \%$ FCS. RNA was analyzed for expression of c-myc mRNAs derived from the endogenous and transfected genes after serum stimulation (Fig. 7a). The endogenous c-myc gene is rapidly induced following serum stimulation, and expression remains high throughout the duration of the experiment $(3 \mathrm{hr})$, in agreement with previously published data (Kelly et al. 1983). The mRNA derived from the transfected gene is not detectable in serum-starved cells (time 0), but is rapidly induced following serum stimulation. After reaching a peak at $60-75 \mathrm{~min}$ after addition of serum, the mRNA begins to decay rapidly,

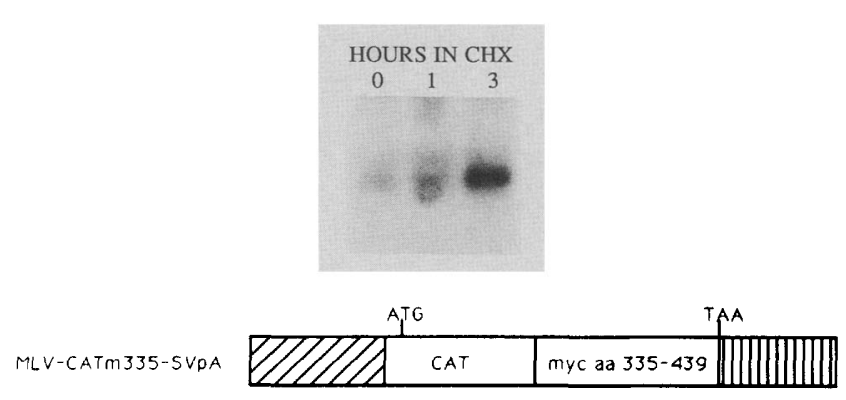

Figure 6. The sequence encoding c-myc amino acids 335-439 can confer inducibility on a CAT-myc fusion gene. (Top) The plasmid MLV-CAT-m335-SVpA was introduced into cells, and expression of the CAT-myc fusion mRNA was measured in the absence and presence of cycloheximide using a CAT probe. (Bottom) A schematic diagram of the plasmid. Symbols are explained in the legend to Fig. 3. 
Figure 7. Direct measurement of the turnover of truncated c-myc transcripts. (a) Cells stably transfected with the plasmid FC4-m23-SVpA were grown in media containing $0.5 \%$ FCS for $48 \mathrm{hr}$; after the addition of $10 \%$ FCS, RNA was isolated at different time points and analyzed for expression of c-myc mRNA from the transfected and endogenous genes. (M) Transcripts from the endogenous gene; $(\mathrm{H})$ transcripts from FC4-m23-SVpA. Numbers represent minutes after the addition of serum. The same filter was then rehybridized with a probe for $\beta_{2}$-microglobulin, which served as a control for RNA loading. The signals from the autoradiograms were analyzed by scanning densitometry, and decay of mRNA from the transfected gene is shown in graph form. The $y$-axis represents the percent mRNA remaining, arbitrarily adjusted to $100 \%$ for the signal at $75 \mathrm{~min}$. The $\mathrm{x}$-axis represents minutes after the addition of serum. A schematic diagram of FC4-m23SVPA is shown; symbols are explained in the legend to Fig. 3. FC4 represents nucleotides -404 to +42 of the human c-fos promotor. $(b)$ Cells stably transfected with the plasmid FC4-m23-SVpA were starved of serum and then induced as in $a$. Actinomycin D was added $75 \mathrm{~min}$ after the addition of serum. RNA samples were analyzed as before. $M$ represents mRNA from the endogenous mouse gene; $(\mathrm{H})$ mRNA from the transfected human gene. The autoradiographic signals were quantitated as before and are shown in graph form. Open squares with dots represent mRNA from the transfected gene; solid squares represent mRNA from the endogenous mouse gene. The axes are as in Fig. $7 \mathrm{a}$.
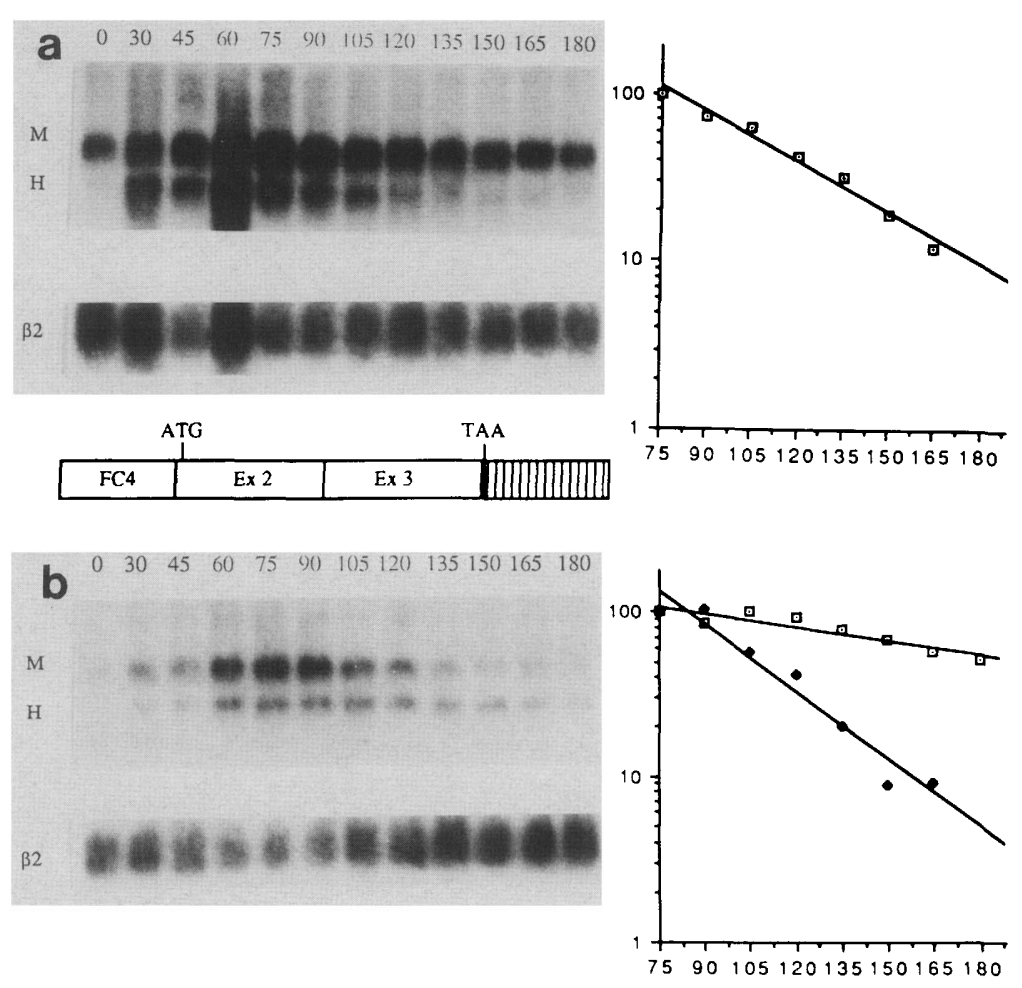

and by 165 min, mRNA from the transfected gene has returned to baseline. The somewhat delayed kinetics of induction compared with mRNA from the endogenous c-fos gene, which reaches maximal levels 30 min after serum stimulation, are probably the result of random integration of the transfected genes into the chromosomal DNA, which may juxtapose elements that slightly perturb temporal control of the c-fos promotor. The same filter was then hybridized with a probe for $\beta_{2}$-microglobulin, which served as a control for RNA loading, and the autoradiograms were analyzed by scanning densitometry to generate a quantitative representation of the data. The graph in Figure 7a shows that beyond $75 \mathrm{~min}$, the level of mRNA from the transfected gene disappears with simple first-order kinetics, with a half-life of $\sim 27 \mathrm{~min}$. Thus, at least at late time points following serum stimulation (>75 min), truncated c-myc transcripts containing only the protein-coding sequence are labile, with the estimate of a 27-min half-life serving as an upper limit for the half-life; any residual transcription from the c-fos promotor at late time points would serve to increase the estimate of the half-life.

A comparison of the half-life of $27 \mathrm{~min}$ obtained in Figure $7 \mathrm{a}$ with the slower turnover (half-life $2.5 \mathrm{hr}$ ) measured by performing actinomycin D chase experiments suggests that actinomycin D may slow the turnover of truncated c-myc mRNAs. Therefore, we measured the effect of actinomycin D on the turnover of transcripts from the plasmid FC4-m23-SVpA. Serum-starved cells expressing the plasmid FC4-m23-SVpA were stimulated with serum; $75 \mathrm{~min}$ after serum stimulation, at a time when mRNA levels have peaked and transcription from the c-fos promotor has returned to baseline, the cells were treated with actinomycin D. The endogenous, fulllength c-myc mRNA turns over rapidly following the addition of actinomycin $\mathrm{D}$, with a half-life of $\sim 21 \mathrm{~min}$, while the mRNA from the transfected FC4-m23-SVpA gene turns over much more slowly, with a half-life of $\sim 110$ min (Fig. 7 b). Thus, actinomycin D significantly slows the turnover of truncated c-myc mRNAs, with the half-life estimated to be $27 \mathrm{~min}$ in the absence of actinomycin D and $110 \mathrm{~min}$ in its presence. Such an effect is not seen on the normal c-myc mRNA, which has a short half-life $(21 \mathrm{~min})$ even in the presence of actinomycin D. The ability of actinomycin D to slow the turnover of c-myc mRNAs is therefore confined to truncated mutant mRNAs. The full-length transcript therefore contains signals that direct rapid turnover even in the presence of actinomycin $\mathrm{D}$; presumably, these are located in the AUrich 3 '-untranslated region.

We have shown that mutations in the translation initiation codon in the plasmid MLV-m23-SVpA result in a loss of inducibility by protein-synthesis inhibitors (Fig. 4). This could be because the mRNA from MLV- 
ATCm23-SVpA is stable; alternatively, this gene may encode a labile mRNA whose turnover is no longer translation dependent. To test between these possibilities, we generated the plasmid FC4-ATCm23-SVpA, which is identical to the plasmid FC4-m23-SVpA except for a mutation in the translation initiation codon from ATG to ATC. After serum stimulation, mRNA derived from this gene is relatively stable, with a half-life of $\sim 150 \mathrm{~min}$ (Fig. 8). This experiment shows that truncated c-myc mRNAs that cannot be translated are stable and also suggests that mRNA from the plasmid MLVATCm23-SVpA is not induced by protein-synthesis inhibitors because it encodes a stable mRNA.

The sequence encoding c-myc amino acids 335-439, when joined in-frame, can confer inducibility by proteinsynthesis inhibitors on a heterologous gene that is otherwise not inducible. The mutational data are consistent with the hypothesis that protein-synthesis inhibitors stabilize an otherwise unstable mRNA and that the sequence encoding c-myc amino acids 335-439 constitutes a mRNA-destabilizing element in the absence of proteinsynthesis inhibitors. We, therefore, tested the hypothesis that this sequence functions as a mRNA-destabilizing sequence by directly measuring the turnover of chimeric CAT-myc mRNAs containing this sequence after transient transcriptional induction of the c-fos promotor.

The plasmid FC4-CAT-SVpA contains the CAT gene under the transcriptional control of the c-fos promotor; likewise, FC4-CATm335-SVpA contains the CAT-myc fusion gene responsive to protein-synthesis inhibitors (sce Fig. 6) under the transcriptional control of the human c-fos promotor. After serum stimulation of stably transfected cells, RNA was collected and analyzed for expression of the recombinant genes as before. The results are shown in Figure 9. Following serum stimulation, there is a rapid induction of CAT mRNA that persists throughout the duration of the experiment (Fig. 9a). Quantitation of the data by scanning densitometry shows that there is essentially no decay of CAT mRNA for $>2 \mathrm{hr}$. In contrast, following induction of the CATmyc fusion mRNA there is a rapid decline to baseline, with a half-life of 29 min measured by densitometry (Fig. $9 \mathrm{~b})$. This is close to our estimate of the half-life of truncated c-myc mRNA (FC4-m23-SVpA; Fig. 7a) of $27 \mathrm{~min}$. Therefore, the sequence that confers inducibility by pro- tein-synthesis inhibitors also functions as an element specifying rapid turnover of the mRNA in the absence of protein-synthesis inhibitors. Together with the mutagenesis studies showing that point mutations in the translation initiation codon abolish inducibility by protein-synthesis inhibitors, these studies strongly support the hypothesis that the sequence encoding c-myc amino acids 335-439 constitutes a mRNA-destabilizing element that functions in a translation-dependent manner.

\section{Discussion}

Treatment of $\mathrm{C} 2$ myoblasts with protein-synthesis inhibitors results in a large increase in the steady-state level of c-myc mRNA. We have analyzed the effect of cycloheximide on the expression of mRNA from several c-myc recombinant genes. We find that disruption of either the translation initiation codon or the sequence encoding c-myc amino acids $371-412$ results in a loss of inducibility by cycloheximide. All other regions of the gene, including the c-myc upstream sequence, the noncoding first exon, the AU-rich 3 '-untranslated region, and the intron sequences are dispensable for this regulation. Consistent with the deletion analysis, fusion of the sequence encoding c-myc amino acids 335-439 to a noninducible gene (MLV-CAT-SVpA) is sufficient to confer inducibility by protein-synthesis inhibitors. The observation that a mutation in the translation initiation codon results in a loss of inducibility, along with the nature of the inducing agent (inhibitors of translation), strongly implies that the mechanism involved is coupled in some way to translation. Whether the recognition element required for this regulation is contained in the c-myc mRNA or the nascent c-myc peptide remains to be answered.

Our results are consistent with the hypothesis that induction of c-myc mRNA by protein-synthesis inhibitors is due to the stabilization of a labile mRNA with a constant rate of transcription. This model requires two features for an mRNA to be induced by protein-synthesis inhibitors: First, the mRNA must be labile in the absence of protein-synthesis inhibitors, and second, its rapid turnover must be blocked by inhibitors of translation, presumably because mRNA degradation is coupled to active translation. One strong prediction of such a

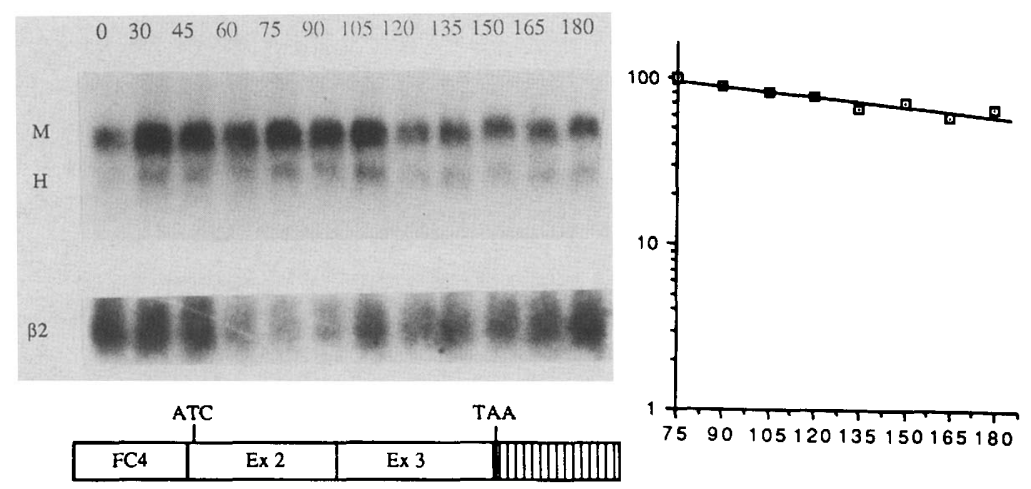

Figure 8. Rapid turnover of truncated c-myc transcripts is dependent on translation. Cells stably transfected with the plasmid FC4-ATCm23-SVpA were starved of serum and then serum stimulated as described in Fig. 7a. RNA samples were collected at different time points after serum stimulation and analyzed as before. (Top) Transcripts from the endogenous (M) and transfected (H) genes; (bottom) $\beta_{2}$-microglobulin mRNA. The graph shows decay of mRNA from the transfected gene vs time; the axes are described in the legend to Fig. 7. A schematic diagram of the plasmid is shown; the symbols are explained in the legend to Fig. 3. 
Figure 9. Direct measurement of the turnover of CAT and CAT-myc mRNAs. Cells stably transfected with either FC4-CAT-SVpA $(a)$ or FC4CATm335-SVpA $(b)$ were grown in media containing $0.5 \%$ FCS for $48 \mathrm{hr}$. After the addition of media containing $10 \%$ FCS, RNA was isolated and analyzed for expression of CAT $|a|$ or CAT-myc $(b)$ transcripts by Northern blotting. (Top) Hybridization to a CAT probe; the filters were then probed for $\beta_{2}$-microglobulin mRNA. The graphs represent levels of mRNA remaining vs. time; the axes are explained in the legend to Fig. 7. Schematic diagrams of the plasmids are shown; the symbols are explained in the legend to Fig. 3.
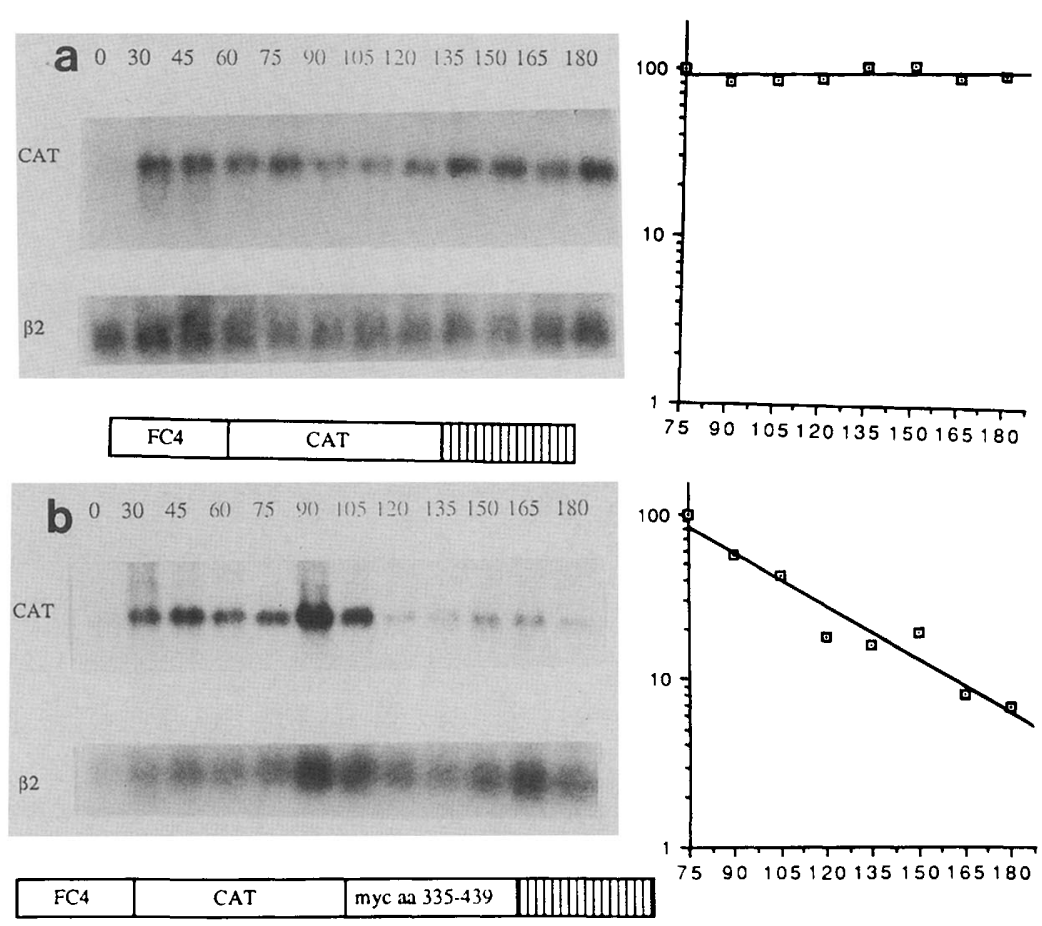

model is that mutant c-myc mRNAs truncated of their $5^{\prime}$ - and $3^{\prime}$-noncoding sequences are unstable, as these mRNAs are induced by cycloheximide to the same degree as the endogenous mRNA. This prediction stands in contrast to previously published data demonstrating that the $3^{\prime}$-untranslated region of $\mathrm{c}-\mathrm{myc}$ mRNA is required for rapid turnover (Jones and Cole 1987). By utilizing the well-characterized c-fos promotor to provide transient transcriptional induction by scrum and monitoring the decay to baseline, we have shown that truncated c-myc mRNAs are indeed labile, with a half-life of $\sim 27 \mathrm{~min}$ (FC4-m23-SVpA; Fig. 7a). We have used this assay to demonstrate that turnover is markedly slowed by actinomycin $\mathrm{D}$, an effect that is specific to truncated mRNAs, and is not seen with the endogenous full-length c-myc transcript (Fig. 7b). Rapid turnover of truncated c-myc transcripts is dependent on translation, as disruption of the translation initiation codon results in a stable mRNA (Fig. 8). Furthermore, we have shown that the sequence identified in the mutational analysis as being sufficient for induction by protein-synthesis inhibitors (Fig. 6) can, in a dominant manner, specify the rapid turnover of a heterologous mRNA (FC4-CATm335SVpA; Fig. 9b). These studies define a sequence in the c-myc protein-coding region that can specify the rapid turnover of mRNAs that contain it in a translation-dependent manner. They also suggest that truncated c-myc transcripts that are stable (Jones and Cole 1987) are due to the pleiotropic effects of actinomycin D.

Our data show that truncated c-myc transcripts are unstable but that their rapid turnover is slowed by actinomycin $\mathrm{D}$. To demonstrate the instability of these transcripts, it was necessary to use a promotor whose activity can be controlled experimentally over short time in- tervals; the c-fos promotor meets this criterion. Because of this experimental limitation, the ability of actinomycin $\mathrm{D}$ to slow the turnover of truncated c-myc mRNAs has been demonstrated directly only under conditions of serum stimulation. Therefore, it remains formally possible that this effect of actinomycin $\mathrm{D}$ is limited to these culture conditions. We feel this is unlikely in view of the fact that the cycloheximide experiments, which support the hypothesis that these mRNAs are labile, were performed without any special manipulations of the culture media.

We have chosen to focus our efforts on defining the mechanism of induction of $c-m y c$ mRNA by inhibitors of translation. Toward this end, we have worked with truncated c-myc genes in an effort to isolate the mRNA destabilizing sequences in the c-myc protein-coding region away from other sequences that are also able to specify rapid turnover, such as the AU-rich sequences in the c-myc $3^{\prime}$-untranslated region (Jones and Cole 1987). We have demonstrated the existence of a signal in the protein-coding region that can specify the rapid turnover of $c-m y c$ mRNA. The signal that we have identified defines a second pathway of mRNA turnover for c-myc mRNA: One pathway functions through the AU-rich $3^{\prime}$-untranslated region of $c-m y c$ mRNA and is not inhibited by actinomycin D (Jones and Cole 1987; Lee et al. 1988); the second pathway functions through the sequence-encoding c-myc amino acids 335-439, is translation dependent, and is sensitive to actinomycin $D$. Which pathway is used to degrade the full-length transcript in the cell under different conditions, how these pathways interact, and how they might be regulated to alter the stability of $c-m y c$ mRNA remains to be determined. 
The existence of two different signals for rapid mRNA degradation has been demonstrated previously for c-fos mRNA (Kabnick and Housman 1988; Shyu et al. 1989). Similar to the results we have obtained, it has been shown that the pathway responsive to one of these signals does not function in the presence of actinomycin D (Shyu et al. 1989). However, in c-fos the actinomycin D-sensitive pathway functions through a signal located in the 3'-untranslated region of the mRNA, and the protein-coding region specifies degradation by a pathway that is not affected by actinomycin D. Whether sensitivity to transcription inhibitors implies any functional or biochemical similarity is an issue yet to be addressed.

Our results address the larger issue of the effect of translation on mRNA turnover. Several mRNAs have been shown to be degraded in a translation-dependent manner, including the mRNAs derived from the histone, TfR, and $\beta$-tubulin genes (Graves et al. 1987; Pachter et al. 1987; Mullner and Kuhn 1988). In contrast, the mRNAs for some stable proteins, such as $\beta$-globin, $\mu$-heavy chain, and triose phosphate isomerase, are apparently stabilized by translation (Maquat et al. 1981; Bauman et al. 1985; Daar and Maquat 1988). The molecular determinants that specify which mRNAs will be degraded in a translation-dependent manner and which will be stabilized by translation are not yet clear, but we have defined one such instability determinant as the sequence encoding c-myc amino acids 335-439. Although we do not yet know whether the signal is in the form of an mRNA sequence or the nascent peptide, precedents exist for both types of recognition (Graves et al. 1987; Mullner and Kuhn 1988; Yen et al. 1988). The sequence we have identified encodes two recently described motifs specifying protein-protein interactions, namely the HLH motif (amino acids 360-396) and the leucine zipper motif (amino acids 403-439) (Landshulz et al. 1988; Murre et al. 1989). By analogy with the mechanism of regulated stability of $\beta$-tubulin mRNA, it is possible that interaction of one of these motifs with another protein is involved in transducing a signal for translation-dependent mRNA degradation (Yen et al. 1988). As deletions of the leucine zipper domain do not inhibit inducibility by cycloheximide, this motif presumably does not mediate interactions leading to mRNA degradation; the role of the HLH motif remains to be addressed by further mutagenesis.

The early-response genes share two forms of regulation. Aside from their defining property, inducibility by mitogens, they are also induced by protein-synthesis inhibitors (Lau and Nathans 1987; Almendral et al. 1988). The conserved responses to both serum and protein-synthesis inhibitors suggests a possible common biochemical mechanism. It has been shown that for many of the early-response genes, including $c-m y c$, changes in the rate of transcriptional initiation cannot account for the changes in the level of steady-state mRNA; therefore, post-transcriptional mechanisms, such as regulated changes in mRNA stability, are likely to be involved. Whether the sequence we have defined as important for translation-dependent mRNA turnover of $c-m y c$ mRNA is involved in serum induction remains to be addressed. However, it should be noted that mitogenic stimuli result in a rapid modification of ribosomes, the phosphorylation of ribosomal protein S6 (Blenis and Erickson 1985; Tabarini et al. 1985). This phosphorylation may play a role in the general increase in translation that is observed following treatment of cells with mitogens, but it could also function to slow the turnover and, therefore permit the accumulation of mRNAs involved in mediating the $G_{0}$ to $G_{1}$ transition. Further studies should allow us to address this intriguing possibility.

\section{Materials and methods \\ Cells and DNA transfections}

All experiments were carried out in C2 myoblasts (Silberstein et al. 1986). C2 cells were grown in Dulbecco's minimum essential (DME) media supplemented with $10 \%$ fetal calf serum (FCS), $5 \% \mathrm{CO}_{2}$, and antibiotics. Test plasmids were cotransfected with the plasmid pSV2neo using the calcium phosphate method, and pools of transfectants $>>50$ individual colonies) were selected by adding G418 in a concentration of $400 \mu \mathrm{g} / \mathrm{ml}$ to the media. Cycloheximide (Sigma) was used at a concentration of $10 \mu \mathrm{g} / \mathrm{ml}$, and actinomycin D (Sigma) was used at a concentration of 10 $\mu \mathrm{g} / \mathrm{ml}$.

RNA isolation and analysis

RNA was isolated by precipitation in $3 \mathrm{M}$ lithium chloride $/ 6 \mathrm{M}$ urea. When the c-myc mRNA generated from the transfected gene could be resolved from the endogenous mouse c-myc transcript in formaldehyde-agarose gels, RNA samples were analyzed by Northern blotting. Hybridizations were carried out according to the method of Church and Gilbert (1984) using probes labeled by random priming. When the transcripts were not well resolved on formaldehyde-agarose gels, samples were analyzed for c-myc expression using an RNase protection assay as described previously (Stone et al. 1987). The PstI fragment of human c-myc exon 2 and the BamHI-SstI fragment of mouse c-myc exon 1 were cloned into the plasmids SP64 or SP65 in an orientation appropriate for the generation of complementary RNA probes. These probes do not yield protected fragments of significant size when hybridized to RNA from the opposite species. All RNA samples were visualized by staining with ethidium bromide to be certain that equal amounts of RNA were probed. When autoradiograms were analyzed by scanning densitometry, the filters were rehybridized with a probe for $\boldsymbol{\beta}_{2}$-microglobulin, and signals for the test mRNAs were normalized to the signals obtained for $\beta_{2}$-microglobulin. Scanning densitometry was carried out on a LKB 2220 Ultrascan XL densitometer, and half-life values were obtained by a least-squares analysis of the values obtained by densitometry for time points beyond $75 \mathrm{~min}$. Only time points beyond $75 \mathrm{~min}$ were used to be certain that transcription from the c-fos promotor had returned to baseline.

\section{Nuclear run-on assays}

Nuclear run-on assays were performed as described by Linial et al. (1985) with one modification. Run-on probe was hybridized to target DNA samples in $0.2 \mathrm{M} \mathrm{Na}_{2} \mathrm{HPO}_{4}$ (pH 7.2), 1 mM EDTA, $7 \%$ SDS, and $1 \%$ bovine serum albumin at $65^{\circ} \mathrm{C}$ for $72 \mathrm{hr}$ (Church and Gilbert 1984). Filters were then washed in $2 \times$ SSC/ $0.1 \% \mathrm{SDS}$ at $65^{\circ} \mathrm{C}$ for $60 \mathrm{~min}$. 


\section{Plasmid constructions}

The normal human c-myc gene is an $8.7-\mathrm{kb}$ HindIII-EcoRI fragment of human genomic DNA cloned into pUC 8.

In many of the plasmid constructs, the MLV-LTR serves as the promotor. The MLV-LTR is contained in a 700-bp fragment of DNA, which contains the U3 and R regions of the LTR, and has been modified to contain a polylinker at its $3^{\prime}$ end, as described previously (Stone et al. 1987). The plasmid pM21 contains the MLV-LTR joined to a unique Xhol site in c-myc that is between $\mathrm{P} 1$ and $\mathrm{P} 2$, the dual c-myc promotors, thus replacing the c-myc upstream sequences with the MLV-LTR. The details of construction of this plasmid have been described previously (Stone et al. 1987).

The plasmid MLV-m23 was created by ligating the MLV-LTR to a ThaI site 75 nucleotides upstream of the intron $1 /$ exon 2 boundary in the human c-myc gene; the c-myc sequences in this plasmid continue to the downstream EcoRI site, except that intron 2 sequences have been deleted by recombining fragments of a human c-myc cDNA. The mRNA derived from this plasmid is predicted to contain the $3^{\prime}$ end of intron 1 , exon 2 , and exon 3. Transcription termination and polyadenylation signals are derived from the human $c-m y c$ gene.

The plasmid MLV-m23-SVpA contains the MLV-LTR fused to a Thal site 5-bp upstream of the translation initiation codon in exon 2; this c-myc cDNA extends to the nucleotides encoding c-myc amino acid 433 where an XhoI site derived from a linker insertion mutant was modified with mung bean nuclease so it could be joined to the HincII-BamHI fragment of the SV40 early region containing signals for transcription termination and polyadenylation. The seven carboxy-terminal amino acids of the c-myc protein (QLVYCSL) and the termination codon encoded by this plasmid are supplied by sequences derived from SV40.

The plasmid MLV-CAT-SVpA was created by ligating the HindIII-SalI fragment containing the MLV-LTR into the HindIII-Sall sites of the plasmid CAT3MS-1, a promotorless CAT construct in which transcription termination and polyadenylation signals are supplied by the early region of the SV 40 virus.

In the plasmid MLV-mCATm3' the coding sequence for CAT replaces the c-myc protein-coding region between amino acids 6 and 433. This was accomplished by ligating the Sall site of CAT3MS- 1 to the XhoI site of c-myc insertion mutant In 6; the $S c a$ I site at the 3 ' end of the CAT-coding region was then ligated to the XhoI site of c-myc insertion mutant In 433 after it had been blunted with mung bean nuclease. Construction of the c-myc insertion mutants has been described previously (Stone et al. 1987). The predicted primary transcript contains sequences from c-myc exon 1 , intron 1 , exon 2 up to c-myc codon 6 , the CAT-coding sequences, and $c-m y c$ sequences extending from $c-m y c$ codon 433 to the normal c-myc polyadenylation signals. The CAT sequences are in a different reading frame from the 5' c-myc sequences so that termination of translation is predicted to occur after 41 amino acids.

Previously described in-frame deletion mutants generated by recombination between different $X$ hoI linker insertion mutants (Stone et al. 1987) were inserted into the plasmid MLV-m23Nsi$\mathrm{SVpA}$ /this plasmid is identical to the plasmid MLV-m23-SVpA except for the presence of 74 bp of c-myc 3'-untranslated sequence downstream of the termination codon). These mutants are named by the numbers of the deleted amino acids.

The plasmid MLV-ATCm23-SVpA was created by using sitedirected mutagenesis to change the $c-m y c$ translation initiation codon in the plasmid MLV-m23-SVpA from ATG to ATC. These plasmids are otherwise identical.

The plasmid MLV-myc1-103CAT-SVpA contains a fusion gene in which the upstream regions of the plasmid MLV-m 23 have been joined at the nucleotides encoding c-myc amino acid position 103 to the downstream sequences of the plasmid MLVCAT-SVpA at the nucleotides encoding CAT amino acid position 34 . The correct reading frames are maintained in this plasmid.

The plasmid MLV-CAT-m335-SVpA contains a fusion gene in which the upstream regions of the plasmid MLV-CAT-SVpA are joined at the nucleotides encoding CAT amino acid 210 to the downstream sequences of the plasmid MLV-m23-SVpA at the nucleotides encoding c-myc amino acid 335 . The correct reading frames are maintained in this plasmid.

In the plasmid FC4-m23-SVpA, the fragment of the human c-fos promotor contained in the plasmid FC4 (Deschamps et al. 1985) has replaced the MLV-LTR in the plasmid MLV-m23$\mathrm{SVpA}$. The c-fos sequences extend from -404 to +42 relative to the transcription start site, and include the DSE (Treisman 1985).

In the plasmid FC4-ATCm23-SVpA, the translation initiation codon of FC4-m23-SVpA has been changed by site-directed mutagenesis from ATG to ATC. These plasmids are otherwise identical.

The plasmid FC4-CAT-SVpA contains the c-fos promoter sequences described above in place of the MLV-LTR in the plasmid MLV-CAT-SVpA.

All enzymes were used according to the manufacturer's specification; when the ends of DNA fragments that were modified before ligation could not be confirmed afterward by restriction enzyme analysis, the relevant junctions were sequenced. Sequencing was carried out using the dideoxy method (Sanger et al. 1977). Site-directed mutagenesis was carried out according to the protocol of Kunkel et al. (1987).

\section{Acknowledgments}

We thank the following people: $K$. Yamamoto and $T$. van Daalen Wetters provided CAT plasmids; I.M. Verma provided the human c-fos promotor fragment; J. White and E. Ralston provided $\mathrm{C} 2$ cells and advice regarding their growth; and P. Bates provided advice regarding site-directed mutagenesis and DNA sequencing. We thank C. V. Dang for thoughtful discussion. R.W. would like to acknowledge the generous support and encouragement of Inder Verma. This work was supported by a National Research Service Award from the National Institutes of Health (R.W.), U.S. Public Health Service grant CA 38783 (W.L.), and a grant from the W.W. Smith Charitable Trust (W.L.).

The publication costs of this article were defrayed in part by payment of page charges. This article must therefore be hereby marked "advertisement" in accordance with 18 USC section 1734 solely to indicate this fact.

\section{References}

Almendral, J.M., D. Sommer, H. Macdonald-Bravo, J. Burckhardt, J. Perera, and R. Bravo. 1988. Complexity of the early genetic response to growth factors in mouse fibroblasts. Mol. Cell. Biol. 8: 2140-2148.

Bauman, B., M.J. Potash, and G. Kohler. 1985. Consequences of frameshift mutations at the immunoglobulin heavy chain locus of the mouse. EMBO I. 4: 351-359.

Bentley, D.L. and M. Groudine. 1986. A block to elongation is largely responsible for decreased transcription of c-myc in differentiated HL-60 cells. Nature 321: 702-706.

Blenis, I. and R.L. Erikson. 1985. Regulation of a ribosomal pro- 
tein S6 kinase activity by the Rous sarcoma virus transforming protein, serum, or phorbol ester. Proc. Natl. Acad. Sci. 82: 7621-7625.

Chavrier, P., M. Zerial, P. Lemaire, J. Almendral; R. Bravo, and P. Charnay. 1988. A gene encoding a protein with zinc fingers is activated during G0/Gl transition in cultured cells. EMBO J. 7: 29-35.

Church, G.M. and W. Gilbert. 1984. Genomic sequencing. Proc. Natl. Acad. Sci. 81: 1991-1995.

Daar, I.O. and L.E. Maquat. 1988. Premature translation termination mediates triosephosphate isomerase mRNA degradation. Mol. Cell. Biol. 8: 802-813.

Deschamps, J., F. Meijlink, and I.M. Verma. 1985. Identification of a transcriptional enhancer element upstream of proto-oncogene fos. Science 230: 1174-1177.

Graves, R.A., N.B. Pandey, N. Chodchoy, and W. F. Marzluff. 1987. Translation is required for regulation of histone mRNA degradation. Cell 48: 615-626.

Greenberg, M.E. and E.B. Ziff. 1984. Stimulation of mouse 3T3 cells induces transcription of the c-fos oncogene. Nature 311: 433-438.

Hann, S.R., M.W. King, D.L. Bentley, C.W. Anderson, and R.N Eisenman. 1988. A non-AUG translational initiation in cmyc exon 1 generates an $\mathrm{N}$-terminally distinct protein whose synthesis is disrupted in Burkitt's lymphomas. Cell 52: 185-195.

Jones, T.J. and M.D. Cole. 1987. Rapid cytoplasmic turnover of c-myc mRNA: Requirement of the $3^{\prime}$ untranslated sequences. Mol. Cell. Biol. 7: 4513-4521.

Kabnick, K.S. and D.E. Housman. 1988. Determinants that contribute to cytoplasmic stability of human c-fos and $\beta$-globin mRNAs are located at several sites in each mRNA. Mol. Cell. Biol. 8: 3244-3250.

Kelly, K., B.H. Cochran, C.D. Stiles, and P. Leder. 1983. Cellspecific regulation of the c-myc gene by lymphocyte mitogens and platelet-derived growth factor. Cell 35: 603-610.

Kozak, M. 1981. Possible role of flanking nucleotides in recognition of the AUG initiator codon by eukaryotic ribosomes. Nucleic Acids Res. 9: 5233-5252.

Kunkel, T.A., J.D. Roberts, and R.A. Zakour. 1987. Rapid and efficient site-directed mutagenesis without phenotypic selection. Methods Enzymol. 154: 367-382.

Landshulz, W.H., P.F. Johnson, and S.L. McKnight. 1988. The leucine zipper: A hypothetical structure common to a new class of DNA binding proteins. Science 240: 1759-1764.

Lau, L.F. and D. Nathans. 1987. Expression of a set of growthrelated immediate early genes in BALB/c 3T3 cells: Coordinate regulation with c-fos or c-myc. Proc. Natl. Acad. Sci. 84: $1182-1186$

Lee, W.M.F., C. Lin, and T. Curran. 1988. Activation of the transforming potential of the human c-fos proto-oncogene requires message stabilization and results in increased amounts of partially modified fos protein. Mol. Cell. Biol. 8: $5521-5527$.

Linial, M., N. Gunderson, and M. Groudine. 1985. Enhanced transcription of c-myc in bursal lymphoma cells requires continous protein-synthesis. Science 230: 1126-1130.

Maquat, L.E., A.J. Kinniburgh, E.A. Rachmeliwitz, and J. Ross. 1981. Unstable $\beta$-globin mRNA in mRNA-deficient $\beta^{0}$ thalassemia. Cell 27: 543-553.

Mullner, E.W. and L.C. Kuhn. 1988. A stem-loop in the $3^{\prime}$ untranslated region mediates iron-dependent regulation of transferrin receptor mRNA in the cytoplasm. Cell 53: 815825.

Murre, C., P.S. McCaw, and D. Baltimore. 1989. A new DNA binding and dimerization motif in immunoglobulin en- hancer binding, daughterless, Myo $D$, and myc proteins. Cell 56: $777-783$

Nepveu, A., R.A. Levine, J. Campisi, M.E. Greenberg, E.B. Ziff, and K.B. Marcu. 1987a. Alternative modes of c-myc regulation in growth factor stimulated and differentiating cells. Oncogene 1: 243-250.

Nepveu, A., K.B. Marcu, A.I. Skoultchi, and H.M. Lachman. $1987 \mathrm{~b}$. Contributions of transcriptional and post-transcriptional mechanisms to the regulation of $c-m y c$ expression in mouse erythroleukemia cells. Genes \&) Dev. 1: 938-945.

Pachter, J.S., T.J. Yen, and D.W. Cleveland. 1987. Autoregulation of tubulin expression is achieved through specific degradation of polysomal tubulin mRNAs. Cell 51: 283-292.

Sanger, F., S. Nicklen, and A. Coulson. 1977. DNA sequencing with chain terminating inhibitors. Proc. Natl. Acad. Sci. 74: $5463-5467$.

Schuler, G.D. and M.D. Cole. 1988. GM-CSF and oncogene mRNA stabilites are independently regulated in trans in a mouse monocytic tumor. Cell 55: 1115-1122.

Shaw, G. and R. Kamen. 1986. A conserved AU-rich sequence from the 3' untranslated region of GM-CSF mediates selective mRNA degradation. Cell 46: 659-667.

Shyu, A., M.E. Greenberg, and J. G. Belasco. 1989. The c-fos transcript is targeted for rapid decay by two distinct mRNA degradation pathways. Genes \&) Dev. 3: 60-72.

Silberstein, L., S.G. Webster, M. Travis, and H.M. Blau. 1986. Developmental progression of myosin gene expression in cultured muscle cells. Cell 46: 1075-1081.

Stone, J., T. deLange, G. Ramsey, E. Jakobovits, J.M. Bishop, H.E. Varmus, and W. Lee. 1987. Definition of regions in human c-myc that are involved in transformation and nuclear localization. Mol. Cell. Biol. 7: 1697-1709.

Swartout, S. and A.J. Kinniburgh. 1989. c-myc mRNA degradation in growing and differentiating cells: Possible alternate pathways. Mol. Cell. Biol. 9:889-902.

Tabarini, D., J. Heirich, and O.M. Rosen. 1985. Activation of S6 kinase activity in 3T3-Ll cells by insulin and phorbol ester. Proc. Natl. Acad. Sci. 82: 4369-4373.

Treisman, R. 1985. Transient accumulation of c-fos RNA following serum stimulation requires a conserved $5^{\prime}$ element and c-fos 3' sequences. Cell 42: 889-902.

Wilson, T. and R. Treisman. 1988. Removal of poly(A) and consequent degradation of c-fos mRNA facilitated by AU-rich sequences. Nature 336: 396-399.

Yen, T.J., P.S. Machlin, and D.W. Cleveland. 1988. Autoregulated instability of $\beta$-tubulin mRNAs by recognition of the nascent amino terminus of $\beta$-tubulin. Nature 334: 580-585. 


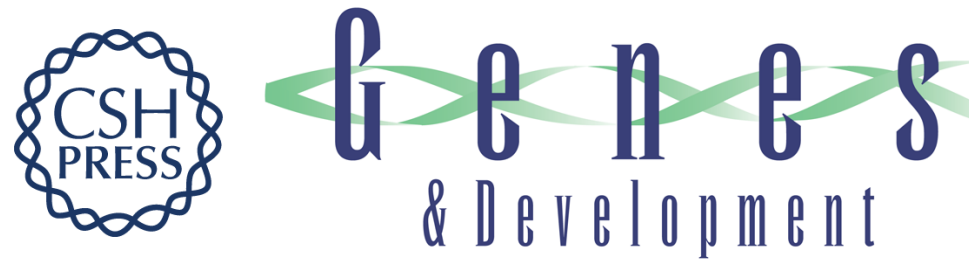

\section{The protein-coding region of c-myc mRNA contains a sequence that specifies rapid mRNA turnover and induction by protein synthesis inhibitors.}

$\mathrm{R}$ Wisdom and W Lee

Genes Dev. 1991, 5:

Access the most recent version at doi:10.1101/gad.5.2.232

References This article cites 37 articles, 16 of which can be accessed free at: http://genesdev.cshlp.org/content/5/2/232.full.html\#ref-list-1

License

Email Alerting Receive free email alerts when new articles cite this article - sign up in the box at the top Service right corner of the article or click here.

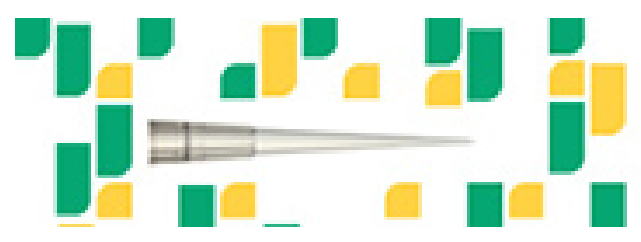

Focused on your science. 